\title{
BreastCore
}

\section{A Review on Breast Cancer Care in Africa}

\author{
Eva J. Kantelhardt ${ }^{a}$ Gizaw Muluken $^{\mathrm{b}}$ Getachew Sefonias $^{\mathrm{b}}$ Ayele Wondimu $^{\mathrm{b}}$ \\ Hans Christoph Gebert ${ }^{a}$ Susanne Unverzagt ${ }^{c} \quad$ Adamu Addissie $^{b}$ \\ ${ }^{\text {a } D e p a r t m e n t ~ o f ~ G y n e c o l o g y, ~ M a r t i n-L u t h e r-U n i v e r s i t y, ~ H a l l e ~(S a a l e), ~ G e r m a n y ; ~}$ \\ ${ }^{b}$ School of Public Health, Addis Ababa University, Addis Ababa, Ethiopia; \\ ${ }^{\mathrm{C}}$ Institute of Medical Epidemiology, Biostatistics and Informatics, Martin-Luther-University, Halle (Saale), Germany
}

Keywords

Africa · Breast neoplasms · Outcome · Therapy · Review

\section{Summary}

Background: The global incidence of breast cancer (BC) is rising, especially in low- and middle-income countries. The purpose of this review is to summarize existing publications on BC care in Africa. Patients and Methods: A systematic search in MEDLINE and smaller databases was carried out to identify African studies on BC treatment, and an additional PubMed search was performed for relevant topics on BC care. Results: A total of 219 publications, mainly from North and West Africa, were found by systematic search. We also selected articles on $\mathrm{BC}$ epidemiology, risk factors, clinical presentation, and cancer control in Africa. Conclusions: Publications on BC treatment are mostly from hospital case series. Evidence on treatment from prospective randomized trials that address the specific characteristics of African patients is lacking. The epidemiologic data shows rising incidences in Africa. The prevalence of risk factors is changing by age group, geographic region, and over time. The clinical picture of BC differs from that of Western countries due to the high proportion of young patients (on account of the African population with a high proportion of young people) and late presentation. Global collaborative efforts are needed to address the rising need for improved BC care in Africa.

(C) 2015 S. Karger GmbH, Freiburg

\section{Introduction}

Non-communicable diseases, including breast cancer (BC), in Africa have been gaining more attention recently since improvements are seen in the management against infectious diseases, poor maternal health, and malnutrition. These days, non-communicable diseases are responsible for more than $60 \%$ of deaths around the world, with more than $80 \%$ of them occurring in low- and middleincome countries. More than $20 \%$ of these deaths from non-communicable diseases are cancer-related deaths [1].

$\mathrm{BC}$ has the highest incidence rate of all cancers in women worldwide (1.67 million) and accounts for over 500,000 deaths annually [2]. It has been said that African patients present late with aggressive tumors and face a lack of therapeutic options, resulting in short survival duration. Data on survival obtained from cancer registries in The Gambia and Uganda in the early years of this century reported an age-standardized 5-year relative survival between only 12 and 46\% [3]. A comparison between West Africans, African Americans, and Caucasian Americans revealed higher proportions of high-grade, early-onset and estrogen receptor-negative cases in African patients [4].

Since the high-level meeting of the United Nations has focused attention on non-communicable diseases (chronic pulmonary and cardiovascular diseases, diabetes, and cancer) in 2011 [5], national cancer control programs have been developed and implemented. Several African first ladies have put the fight against female cancer (BC and cervical cancer) at the top of the national agenda [6]. This has encouraged clinicians and researchers in various countries to improve activities and to publish evidence available on the topic. Considering the huge diversity of the African continent in terms of ethnicities and genetic background, socio-economic development and health system status, culture and behavior, and many other areas, it is difficult to talk about BC in Africa in general. We used geographical divisions (West, North, South, East, and Central Af- 
Table 1. Publications according to years and regions, with the population in 2012 indicated

\begin{tabular}{|c|c|c|c|c|c|c|c|c|c|c|c|c|c|}
\hline \multirow{2}{*}{$\begin{array}{l}\text { Years } \\
2010-2014\end{array}$} & \multirow{2}{*}{$\begin{array}{c}\text { Total } \\
72\end{array}$} & \multicolumn{2}{|c|}{$\begin{array}{l}\text { North Africa, } \\
207 \text { million }\end{array}$} & \multicolumn{2}{|c|}{$\begin{array}{l}\text { West Africa, } \\
320 \text { million }\end{array}$} & \multicolumn{2}{|c|}{$\begin{array}{l}\text { East Africa, } \\
352 \text { million }\end{array}$} & \multicolumn{2}{|c|}{$\begin{array}{l}\text { Central Africa, } \\
133 \text { million }\end{array}$} & \multicolumn{2}{|c|}{$\begin{array}{l}\text { Southern } \\
\text { Africa, } \\
58 \text { million }\end{array}$} & \multicolumn{2}{|c|}{ Regional } \\
\hline & & $33^{\mathrm{a}}$ & $45.8 \%$ & 21 & $29.2 \%$ & 8 & $11.1 \%$ & 4 & $5.6 \%$ & 3 & $4.2 \%$ & 3 & $4.2 \%$ \\
\hline $2005-2009$ & 54 & 20 & $37.0 \%$ & 22 & $40.7 \%$ & 6 & $11.1 \%$ & & & 6 & $11.1 \%$ & & \\
\hline 2000-2004 & 35 & 14 & $40.0 \%$ & 10 & $28.6 \%$ & 2 & $5.7 \%$ & & & 9 & $25.7 \%$ & & \\
\hline 1995-1999 & 15 & 3 & $20.0 \%$ & 2 & $13.3 \%$ & 1 & $6.7 \%$ & 1 & $6.7 \%$ & 8 & $53.3 \%$ & & \\
\hline$<1995$ & 43 & 5 & $11.6 \%$ & 16 & $37.2 \%$ & 2 & $4.7 \%$ & 1 & $2.3 \%$ & 16 & $37.2 \%$ & 3 & $7.0 \%$ \\
\hline Total & 219 & 75 & $34.2 \%$ & 71 & $32.4 \%$ & 19 & $8.7 \%$ & 6 & $2.7 \%$ & 42 & $19.2 \%$ & 6 & $2.7 \%$ \\
\hline
\end{tabular}

${ }^{\mathrm{a} C o u n t r i e s ~ w i t h ~ t h e ~ h i g h e s t ~ n u m b e r s ~ d u r i n g ~ t h e ~ t i m e ~ p e r i o d ~ i n d i c a t e d ~ i n ~ i t a l i c s . ~}$
Fig. 1. Results of the systematic review: PRISMA flow chart.

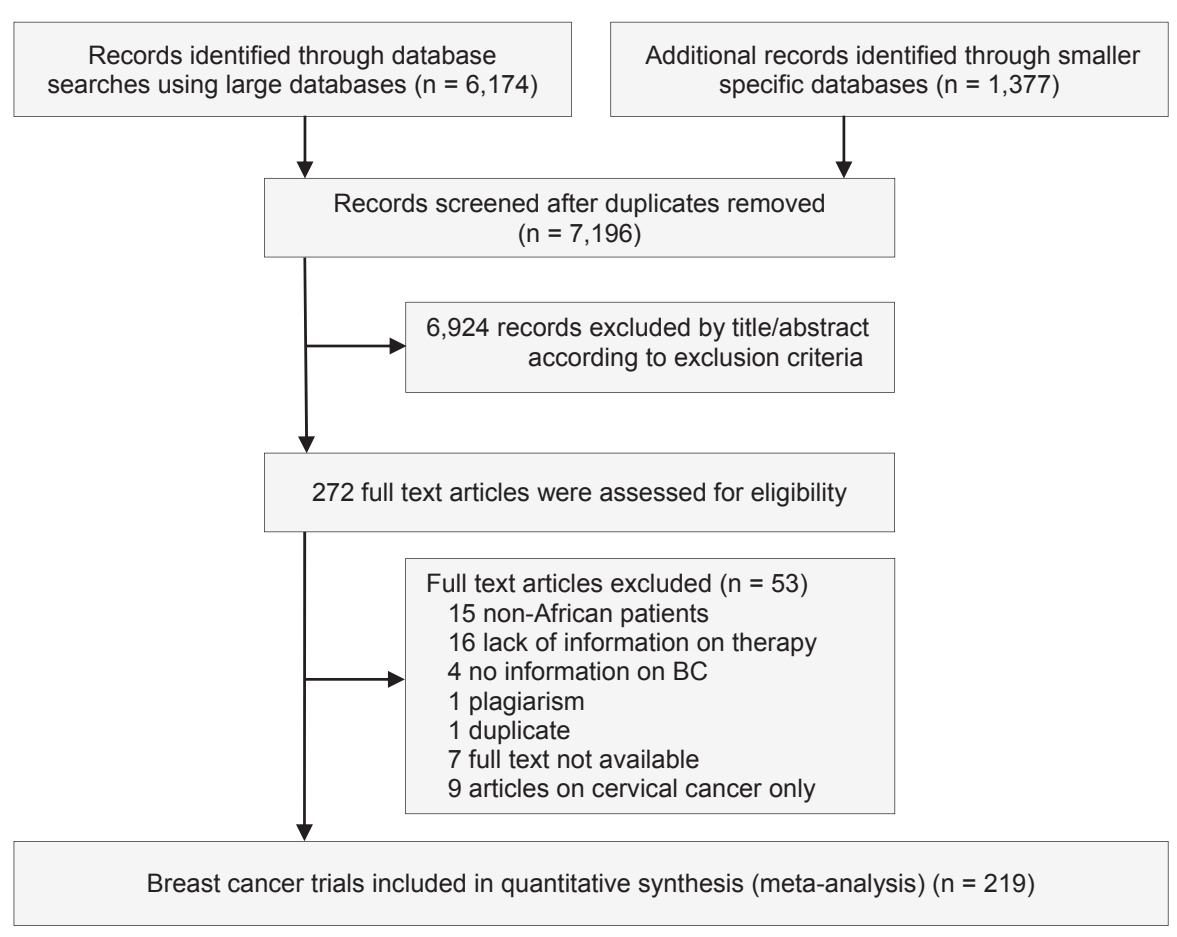

rica) to group the results of our literature search. The scope of this systematic review is to give a quantitative overview on the articles available in the common large databases, as well as in the regional African databases, up until April 2014 on BC therapy and outcomes in Africa. For a qualitative review on BC care in general, we selected relevant articles less than 5 years old and added important previous work. First, we will give an overview on time trends, regional differences and the methodology of publications. Then, the relevant most recent articles on $\mathrm{BC}$ health care are discussed. Major challenges for BC care in Africa are summarized.

\section{Methodology}

We performed a systematic search in MEDLINE (Ovid), CENTRAL, African Journals Online (AJOL), African Index Medicus, The Breast Health Global Initiative, POPLINE, and SurvCan to identify all publications related to clinical and observational studies describing female cancer (breast and cervix) and Africa. Within this general search, we selected all publications related to treatment and/or outcomes in Africa. All publications were screened by title, keywords, abstract, and full text for relevant publications. Inclusion criteria were all stud- ies describing treatment and/or outcomes of $\mathrm{BC}$ in Africa. Exclusion criteria were cross-sectional studies without information on therapy, studies on screening methodology, studies on pathologic material, studies only on African Americans, and studies conducted on non-African patients.

Additionally, we performed a search in MEDLINE (PubMed) for relevant topics on $\mathrm{BC}$ care, such as burden, awareness, risk factors, tumor biology, and healthcare services (PubMed search for 'Breast neoplasm AND Africa'). For this review, relevant articles from the last 5 years and selected articles from before are presented here as a brief overview, and major challenges are discussed.

\section{Systematic Review on BC Treatment and Outcomes}

This systematic review was carried out to review evidence on BC treatment in Africa.

\section{Results and Discussion of the Search}

Having used the above-mentioned inclusion and exclusion criteria to identify potentially relevant articles, we identified a total of 7,154 publications on the treatment of female cancer (BC and cervical cancer), of which we found 6,174 in the large databases: 
Table 2. Publications according to years and top countries

\begin{tabular}{lcccllc}
\hline & Total & $\begin{array}{l}2010- \\
2014\end{array}$ & $\begin{array}{l}2005- \\
2009\end{array}$ & $\begin{array}{l}2000- \\
2004\end{array}$ & $\begin{array}{l}1995- \\
1999\end{array}$ & $<1995$ \\
\hline Nigeria & 56 & $16^{\mathrm{a}}$ & 16 & 8 & 1 & 15 \\
South Africa & 42 & 3 & 6 & 9 & 8 & 16 \\
Egypt & 33 & 15 & 10 & 3 & 3 & 2 \\
Morocco & 23 & 13 & 2 & 7 & & 1 \\
Tunisia & 17 & 4 & 7 & 4 & & 2 \\
\hline
\end{tabular}

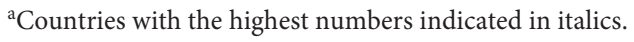

MEDLINE (by Ovid; March 26, 2014; $\mathrm{n}=5,745$ ) and Cochrane (March 27, 2014; $\mathrm{n}=429$ ). We found 980 publications in smaller databases (AJOL; April 23, 2014; $\mathrm{n}=281$ ): African Index Medicus (May 7, 2014; $\mathrm{n}=153$ ), The Breast Health Global Initiative (May 7 , 2014; $\mathrm{n}=99$ ), POPLINE (May 9, 2014; $\mathrm{n}=340$ ), and SurvCan (May 22, 2014; $\mathrm{n}=107$ ). In total, 938 publications were thought to be of relevance and the full papers were assessed. Of those, 219 publications were included in this review.

In general, we noted an increase in the number of publications available in the databases searched, from 15 articles in 1995-1999 to 72 articles in 2010-2014 (fig. 1). The majority of papers $(n=75)$ originated in North Africa (population in 2012: 207 million), closely followed by West Africa ( $\mathrm{n}=71$; population in 2012: 320 million). Southern Africa ( $\mathrm{n}=42$; population in 2012: 58 million) dominated before the year 2000. There were few publications from East ( $\mathrm{n}=1$ 19; population in 2012: 352 million) and Central Africa ( $\mathrm{n}=6$; population in 2012: 133 million), but the number of studies has increased since the 1990s (table 1). This may reflect the socioeconomic development of the countries and the availability of advanced medical service in the North African region.

When comparing the number of physicians per population, there are notable differences seen in the large countries of each region. Egypt and Algeria had the highest numbers (2.83 and 1.21 per 1,000 people in 2008 and 2007), South Africa had 0.77 per 1,000 people in 2004, Nigeria had 0.395 per 1,000 people in 2008 , and Ethiopia and Tanzania had only 0.022 and 0.008 per 1,000 people in 2007 and 2006 [7]. This reflects the focus of primary healthcare mainly involving non-physicians in East Africa (e.g. Tanzania), as opposed to a more clinical approach with more physicians in West Africa. Since there are fewer physicians in East Africa, this can possibly explain the relatively low number of articles on $\mathrm{BC}$ therapy from this region.

Looking at the individual countries, we noted that Nigeria was the number one country in terms of the overall number of publications, and specifically since 2005. Before 2005, South Africa was the country with the most articles available. It is possible that the case of scientific misconduct during the high-dose chemotherapy BC trial from South Africa may have led to reduced activities in BC research [8]. Egypt, Morocco, Tunisia, and Ghana followed with an overall number of 10 or more articles (table 2). These data are in line with the large population size and advanced socio-economic status of these countries.
Types of Studies Published

The studies were classified based on the type of treatment, the study design, and the grading of levels of evidence (LoE) (supplemental table 1,www.karger.com/?DOI=4433156). The therapies described in the articles were mainly surgery (70\%), followed by chemotherapy $(60 \%)$, radiotherapy $(46 \%)$, and endocrine treatment (38\%). Targeted treatment was rarely described. We note that surgery was the main focus and probably also the most widely applied therapy for BC patients. Finding that $60 \%$ of articles analyze or mention chemotherapy may indicate that systemic therapy is also used. However, finding that only $38 \%$ of articles analyze endocrine therapy indicates an increased need for more focus on this inexpensive and well-tolerated treatment option [9].

In most cases, descriptive studies (43\%) were conducted. We found few randomized controlled trials (9\%) and only $25 \%$ trials in total. There were also $5 \%$ reviews. The influence of therapy was reported in $53 \%$ of the articles; median survival was reported in $28 \%$. Toxicities were mentioned in $21 \%$. We found 23 meta-analyses. When looking at LoE criteria according to the Oxford definition [10], most articles showed LoE 4 (72\%).

\section{Epidemiology of BC in Africa}

Recently, a total number of the 26 population-based registries in 20 countries were assembled in the African Cancer Registry Network (AFCRN) and contributed data to the GLOBOCAN 2012 database [11]. The report estimated that the incidence rates vary nearly 4-fold across various regions of the world, with rates ranging from 27 per 100,000 in Middle Africa and Eastern Asia to 96 per 100,000 in Western Europe. Higher incidence rates occur in countries with established screening programs. $\mathrm{BC}$ is the most commonly diagnosed cancer in Africa annually, with an estimated 63,100 cancer deaths in 2012 [2, 12].

The incidence rates vary considerably within Africa. Population-based, age-standardized data from Kenya (Nairobi) revealed an age-standardized incidence rate of 52 per 100,000 in 2004-2008 [13]. Population-based data from Zimbabwe and Uganda during the same time period showed rates of 33 and 34 per 100,000 women, respectively $[14,15]$. Results from Malawi (national data) are even lower, showing an annual incidence of 4 per 100,000 women [16]. Since registration methods are similar, reasons for this diversity may be lack of access to health service, lack of pathologic diagnosis, or true differences in risk factors.

Recently, several population-based cancer registries published their data analyzing trends over a period of 15-20 years. The 20year incidence trend among the black population of Zimbabwe increased by about $4.9 \%$ annually, on average. The increases were more evident in older age groups (above age 50 years) than among the young [14]. In Uganda, the annual increase in incidence between 1991 and 2010 was 3.7\% [15]. In Mozambique, the incidence of BC increased from $13.7 / 100,000$ in 1991-1996 to $26.2 / 100,000$ in 2003-2008, with relevant increases of $6.5 \%$ annually, on average. The greatest changes were seen among postmenopausal women 
[17]. The possible reason for the increasing BC incidence was suggested as adoption of Western habits, especially among the urban population, leading to lower fertility rates and a higher frequency of obesity. In South Africa, a recent article from a rural area showed that the annual incidence in women was only 12.2 per 100,000 in 2012, with an annual increase of $4.3 \%$ since 1998. It is likely that reproductive factors and the lifestyle in the rural areas are still protective against $\mathrm{BC}$, but even here changes are being noticed [18].

Altogether, increases in age-standardized $\mathrm{BC}$ incidences of between 3.7 and $6.5 \%$ annually are seen. This alarming fact has to be considered when planning healthcare service capacities and awareness campaigns for the upcoming years.

\section{Risk Factors and Prognostic Factors of BC in Africa}

A different picture of $\mathrm{BC}$ in Africa concerning the incidence, the tumor biology, and the population and its risk factors and outcome is seen. Comparing Caucasian and African American patients has revealed differences in tumor biology leading to differences in outcomes. Lower incidence rates, but higher mortality, are reported. Younger age and a higher risk of triple-negative tumors lead to reduced survival in African Americans [19]. The majority of African studies are hospital-based case-control studies with small numbers.

Brinton et al. [20] reviewed the literature on risk factors for BC in African women. Higher parity (as in Africa) is generally considered protective - but may possibly lead to a transient increase in risk for premenopausal $\mathrm{BC}$, with subsequent decreases at the postmenopausal age. Breastfeeding as a protective factor was found, but some studies only showed a weak or no effect. Higher socioeconomic status was found to be a risk factor in several studies; this could also be a surrogate for the prevalence of other risk factors (obesity, fewer children, etc.). In addition, better health-seeking behaviors may increase the number of diagnoses made in the higher socio-economic bracket. A strong correlation between BC and height was found in several studies, as well as the correlation between higher waist circumference and waist-to-hip ratio to $\mathrm{BC}$ risk. A large case-control study from South Africa revealed increases in $\mathrm{BC}$ risk during the use of hormonal contraceptives, especially progesterone-alone (injectable) options [21]. There is, up to now, a lack of epidemiological studies addressing environmental factors, physical activity, medical history, toxic agents, and most dietary factors including alcohol. Factors unique to Africa may include infectious agents such as the microbiome, human immunodeficiency virus (HIV) prevalence, and malaria. Environmental agents, such as fertilizers, insecticides including DDT, skin lighteners and hair relaxers, may also influence the susceptibility to BC [20].

$\mathrm{BC}$ incidence rates are very low in North Africa. Corbex et al. [22] postulated that the risk factors are similar throughout Africa but that the prevalence varies considerably. They looked at the pattern of risk factors in North Africa compared to Western countries to see if this may explain the low rate of $\mathrm{BC}$, as well as the unique patterns of BC in North Africa, such as early onset, aggressive forms (e.g. inflammatory BC), or high proportions of male BC. In North Africa, the presence of protective factors, especially during the 1980s, was more dominant than in Western countries. The mean number of children, early age at first childbirth, longer duration of breastfeeding, higher age at menarche, early menopause, little use of hormonal contraceptives, less alcohol consumption, and lower body mass index lead to a low-risk profile, which is now more evident in the elderly than in the younger North African women.

When looking at age-specific incidence rates, young age groups show similar BC rates compared to Western countries whereas the older age groups (above age 50 years) have markedly reduced incidence rates. Lack of screening in older age groups may also lead to lower detected incidence rates. Thus, the proportion of $\mathrm{BC}$ at a young age is higher due to a lower detected incidence in older women, and does not necessarily reflect different African tumor biology. The same applies to male $\mathrm{BC}$, where the proportion is higher due to lower numbers of postmenopausal $\mathrm{BC}$ in women. The lower incidence of $\mathrm{BC}$ in postmenopausal women also leads to higher proportions of inflammatory $\mathrm{BC}$, as reported in various case series. These observations may explain the difference in the $\mathrm{BC}$ pattern in North Africa, which does not necessarily point to a different biology of the disease but rather to a difference in the population structure [22].

Eng et al. [23] published a large meta-analysis on articles describing hormone receptor status and human epidermal growth factor receptor 2 (HER2) status in Africa. They reported on 80 studies, including nearly 17,000 tumors. The proportion of estrogen receptor-positive disease was between 20 and $80 \%$. Influencing factors on the proportion of estrogen receptor-positive disease included the use of archived tissue compared to prospectively collected tissue, the year of collection, and the higher proportion of grade 3 tumors, which had less estrogen receptor-positive cases. The more recent and prospectively collected series showed that the majority of cases were estrogen receptor positive. This should encourage the use of tamoxifen as a simple and inexpensive treatment option, even in cases where the receptor status is unknown.

In summary, reproductive and lifestyle risk factors according to small studies from Africa were found similar to those in Western patients, but differences in population structure and risk factor prevalence have to be considered when looking at patient cohorts from Africa. It is possible that larger cohort studies would reveal differences in known risk factors and there could also be unique factors (e.g. fertilizers, co-infections) that contribute to the BC risk in Africa.

\section{Clinical and Pathological Presentation of BC}

Clinical and pathological factors will be discussed on the basis of articles from 7 African countries: Republic of South Africa (RSA) [24], Egypt [25-27], Nigeria [28], Eritrea [29], Morocco [30], Cameroon [31, 32], and Rwanda [33]. 
All articles reported that the majority of women presented at the healthcare facility with advanced BC (stages III and IV). Factors that influence the lack of early healthcare-seeking practices include distance to the healthcare facility (RSA and Egypt), the tendency to wait until experiencing pain (Egypt), a lack of knowledge regarding breast self-examination (Egypt), residing in a rural area (RSA), advanced age (RSA and Egypt), low literacy rates (RSA, Egypt, Nigeria), low income (RSA and Egypt), lack of knowledge regarding the illness (Nigeria), pursuing traditional treatment and the belief in supernatural healing. Being single and premenopausal were also risk factors for delayed presentation and diagnosis (Nigeria).

The majority of the patients described were $\leq 50$ years old (all articles). 3 papers reported on male $\mathrm{BC}$, with a proportion between 1 and 6\% (Cameroon, Rwanda, and Eritrea). Self-examination was found to be the primary method of first detecting the BC, but very few patients underwent other examination procedures (Cameroon). At the time of the initial diagnosis, the majority of the women had already developed clinically positive lymph nodes and had major organ metastasis, mainly to the lungs, bones, and liver (Cameroon, Eritrea).

In conclusion, there is a low level of early health-seeking practices among women with BC in Africa. Sociodemographic, economic, and behavioral factors lead to advanced cancer stages by the time the women present for diagnosis. Specifically identifying the problematic areas and approaching them will contribute to improving $\mathrm{BC}$ patient outcomes by reducing the average stage at presentation ('downstaging').

\section{Surgery and Adjuvant Treatment of BC}

Considering the limited facilities for radiation, mastectomy is the surgical treatment of choice for operable cases in many African countries. In Nigeria, 35.2\% of the newly diagnosed BC patients (n $=1,226$ ) underwent mastectomy, and half of these had received primary systemic chemotherapy. The majority of patients were treated with palliative intention without surgery due to advanced disease [34]. A case series from Egypt analyzing breast tumor management found that over half of the patients presented with stage III or IV BC. Of all surgical cancer cases, $68 \%$ were treated by modified radical mastectomy; the authors suspect that surgeons prefer this option since compliance to radiotherapy after breast conservation may be poor despite available facilities [35]. The lack of availability of radiotherapy still remains a significant challenge, with an estimated current coverage of $28 \%$ and the need for another 703 machines in Africa [36].

Primary systemic chemotherapy is an important treatment component when looking at the high proportions of advanced disease. A phase II trial from Nigeria that included 16 patients who received primary systemic capecitabine for over 24 weeks found that the overall response was $44 \%$ after 8 cycles [37]. A study from Egypt reported on gemcitabine and cisplatin in locally advanced or metastatic BC after previous anthracycline therapy. In 132 patients, there was a $33 \%$ response rate and a $46 \%$ rate of stable disease was seen [38]. A study from Egypt compared anthracycline-based chemotherapy with or without docetaxel in estrogen receptor-positive pT1-2 BC $(n=60)$. The addition of taxanes did not improve the 4-year disease-free survival [39].

Altogether, we found only a few articles of clinical trials conducted in Africa and especially addressing specific features such as advanced stage, treatment availability, and comorbidities (e.g. HIV infection).

\section{Cancer Control in Africa}

We reviewed articles in the African context related to the health system efforts made for prevention, screening, and treatment to reduce the burden associated with BC. There are studies that suggest early detection and intervention as cost-effective ways to avert the daily-adjusted life years lost (DALYS). One study discussed that mammography screening, in combination with treatment at all stages, is a cost-effective intervention for BC that would likely prevent more DALYS [40]. However, others argue that biennial screening by clinical breast examination (CBE) and rising mass media awareness were more effective at reducing the DALYS than mammography screening [41]. Mammography screening may become the preferred option in the future, but currently, due to the very young population which is not eligible and due to resource constraints, this option is not suitable for the majority of Africa's sub-Saharan countries [42].

In Ethiopia, it was found that the women's first visits to the healthcare service providers were initiated due to changes in or the addition of symptoms, family pressure, or secondary to other careseeking behaviors [43]. The patient navigation chain has a lot of barriers until the patients eventually reach the central cancer center. At a minimum, patients face 3 or more nodes that are widely divergent [44]. A study done in Ghana found that being a member of the Islamic religion, seeking treatment at traditional healers, and a lack of awareness of national health insurance coverage for $\mathrm{BC}$ treatment were the main factors that affected treatment completion [45]. A hospital-based study from Ghana revealed that patients diagnosed with late-stage cancer who were put on adjuvant therapy with hormone receptor status evaluation were more adherent to the treatment guidelines compared with those that never had the hormone receptor status determined [46]. A population-based survey from Rwanda and Sierra Leone, looking at the prevalence of breast masses and barriers to care, showed that women were not seeking medical care due to the absence of symptoms of the breast masses, financial issues, and trust in traditional healers, as well as an overall distrust towards the medical system [47].

Late stage at diagnosis is a problem for BC control [40, 48, 49]. In Ghana, a study showed that $64.1 \%$ of patients presented to facilities at a late stage of the disease for diagnosis [46]. There are significant efforts being made to optimize treatment with limited resources; for example, Rwanda established a central BC treatment center [50]. Authors from Tanzania demonstrated that a cost-ef- 
fective low-technology interventional study resulted in an improvement of early detection and downstaging at diagnosis. Proactive visitation of health aides to the villages for the early detection of BC and other cancers was effective. The study found an increasing number of early-stage BCs (stages I and II) in the intervention villages during the 1 st, 2 nd, and 3 rd year at $9 \%, 60 \%$, and $67 \%$, respectively [49].

In summary, early detection and treatment are the main interventional approaches for $\mathrm{BC}$ control. The patient's sociodemographic and behavioral factors, community culture and beliefs, healthcare service availability, and navigation-related factors are important considerations for $\mathrm{BC}$ control programs. Interventions to improve the outcomes and the overall healthcare system, like a combination of treatments at all stages, awareness generation by media coverage, the use of community health workers, and the use of health data based on research, are very effective. Resource constraints are very demanding in making use of and sustaining such interventions. Resource-stratified guidelines for BC were recently published as an initiative from the National Comprehensive Cancer Network [51]. The 4 levels are 'Basic', 'Limited', 'Enhanced', and 'NCCN Guidelines at centers of excellence in the United States'. These guidelines can be adapted according to the individual setting.

\section{Conclusions}

$\mathrm{BC}$ is an emerging topic in Africa according to the annually increasing numbers of published articles. Still, evidence on therapy and outcome is mainly available from cohort studies. Up to now, only few prospective clinical trials have been published that include issues specific to Africa, such as patients with young age and advanced tumor stages, co-infections, and limited resources. By now, data from population-based cancer registries have become available for the majority of African countries. Age-standardized BC incidence rates show regional differences and increase over time. The reasons include better diagnosis and changing risk factors in a population in transition, like, e.g., reproductive factors, lifestyle, etc. African physicians are faced with many young patients due to the shape of the African population pyramid and with late-stage tumors due to delays in accessing health care. Mastectomy is the surgery of choice because of a lack of radiation facilities; primary systemic therapy as an option for locally advanced disease is available in oncology centers. As compared to earlier reports, recent studies show higher proportions of estrogen receptor-positive cases, suggesting advantages of endocrine therapy for patients with unknown receptor status. Cancer control in Africa mainly involves activities to downstage the cases at presentation and to equip the healthcare systems with capacities to provide regional and systemic treatment. This needs political prioritization and efforts of the scientific community to provide evidence for the specific African context.

\section{Online Supplemental Table}

Supplemental Table 1. Publications on breast cancer according to topic, design, and region, with the population in 2012 indicated

To access the online supplemental table, please refer to www.karger.com/ ?DOI $=4433156$.

\section{Disclosure Statement}

This study was supported by German Ministry of Education and the Research Grant 01DG13026. There are no financial disclosures for any author.

\section{References}

1 World Health Organization (WHO): Deaths from NCDs. www.who.int/gho/ncd/mortality_morbidity/ ncd_total_text/en/, 2015.

2 Ferlay J, Soerjomataram I, Dikshit R, Eser S, Mathers C, Rebelo M, Parkin DM, Forman D, Bray F: Cancer incidence and mortality worldwide: sources, methods and major patterns in GLOBOCAN 2012. Int J Cancer 2015;136:E359-E386

3 Sankaranarayanan R, Swaminathan R, Brenner H, Chen K, Chia KS, Chen JG, Law SC, Ahn YO, Xiang YB, Yeole BB, Shin HR, Shanta V, Woo ZH, Martin N, Sumitsawan Y, Sriplung H, Barboza AO, Eser S, Nene BM, Suwanrungruang K, Jayalekshmi P, Dikshit R, Wabinga H, Esteban DB, Laudico A, Bhurgri Y, Bah E, Al-Hamdan N: Cancer survival in Africa, Asia, and Central America: a population-based study. Lancet Oncol 2010;11:165-173.

4 Huo D, Ikpatt F, Khramtsov A, Dangou J, Nanda R, Dignam J, Zhang B, Grushko T, Zhang C, Oluwasola O, Malaka D, Malami S, Odetunde A, Adeoye AO, Iyare F, Falusi A, Perou CM, Olopade OI: Population differences in breast cancer: survey in indigenous African women reveals over-representation of triple-negative breast cancer. J Clin Oncol 2009;27:4515-4521.
5 United Nations: Report of the Formal Meeting of Member States to conclude the work on the comprehensive global monitoring framework, including indicators, and a set of voluntary global targets for the prevention and control of noncommunicable diseases. http://apps.who. int/gb/NCDs/pdf/A_NCD_2-en.pdf, 2012.

6 Oluwole D, Kraemer J: Innovative public-private partnership: a diagonal approach to combating women's cancers in Africa. Bull World Health Organ 2013;91: 691-696.

7 Gapminder: Diverse free material. www.gapminder. org/data/ [last accessed August 4, 2015].

8 Horton R: After Bezwoda. Lancet 2000;355:942-943.

9 Davies C, Godwin J, Gray R, Clarke M, Cutter D, Darby S, McGale P, Pan HC, Taylor C, Wang YC, Dowsett M, Ingle J, Peto R: Relevance of breast cancer hormone receptors and other factors to the efficacy of adjuvant tamoxifen: patient-level meta-analysis of randomised trials. Lancet 2011;378:771-784.

10 Phillips B, Ball C, Sackett D, Badenoch D, Straus S, Haynes B, Dawes M: Oxford Centre for Evidencebased Medicine - Levels of Evidence (March 2009). www.cebm.net/oxford-centre-evidence-based-medicinelevels-evidence-march-2009/, 2009 [last accessed September 9, 2015].
11 African Cancer Registry Network: AFCRN African Cancer Registry Network. www.afcrn.org/ [last accessed June 12, 2014]

12 Parkin DM, Bray F, Ferlay J, Jemal A: Cancer in Africa 2012. Cancer Epidemiol Biomarkers Prev 2014;23: 953-966.

13 Korir A, Okerosi N, Victor R, Mutuma G, Parkin M: Incidence of cancer in Nairobi, Kenya (2004-2008). Int J Cancer 2015;137:2053-2059.

14 Chokunonga E, Borok MZ, Chirenje ZM, Nyakabau AM, Parkin DM: Trends in the incidence of cancer in the black population of Harare, Zimbabwe 1991-2010. Int J Cancer 2013;133:721-729.

15 Wabinga HR, Nambooze S, Amulen PM, Okello C, Mbus L, Parkin DM: Trends in the incidence of cancer in Kampala, Uganda 1991-2010. Int J Cancer 2014; 135:432-439.

16 Msyamboza K, Dzamalala C, Mdokwe C, Kamiza S, Lemerani M, Dzowela T, Kathyola D: Burden of cancer in Malawi; common types, incidence and trends: $\mathrm{Na}$ tional Population-Based Cancer Registry. BMC Res Notes 2012;5:149. 
17 Lorenzoni C, Vilajeliu A, Carrilho C, Ismail MR, Castillo P, Augusto O, García-Basteiro AL, Sidat M, Sanjosé S de, Menéndez C, Ordi J, Ahmad A: Trends in cancer incidence in Maputo, Mozambique, 1991-2008. PLoS ONE 2015;10:e0130469.

18 Somdyala NI, Parkin DM, Sithole N, Bradshaw D: Trends in cancer incidence in rural Eastern Cape Province; South Africa, 1998-2012. Int J Cancer 2015; 136:E470-E474.

19 Newman LA: Breast cancer disparities: high-risk breast cancer and African ancestry. Surg Oncol Clin N Am 2014;23:579-592.

20 Brinton LA, Figueroa JD, Awuah B, Yarney J, Wiafe S, Wood SN, Ansong D, Nyarko K, Wiafe-Addai B, Clegg-Lamptey JN: Breast cancer in sub-Saharan Africa: opportunities for prevention. Breast Cancer Res Treat 2014;144:467-478.

21 Urban M, Banks E, Egger S, Canfell K, O’Connell D, Beral V, Sitas F: Injectable and oral contraceptive use and cancers of the breast, cervix, ovary, and endometrium in black South African women: case-control study. PLoS Med 2012;9:e1001182.

22 Corbex M, Bouzbid S, Boffetta P: Features of breast cancer in developing countries, examples from North Africa. Eur J Cancer 2014;50:1808-1818.

23 Eng A, McCormack V, dos-Santos-Silva I: Receptordefined subtypes of breast cancer in indigenous populations in Africa: a systematic review and meta-analysis. PLoS Med 2014;11:e1001720.

24 Dickens C, Joffe M, Jacobson J, Venter F, Schüz J, Cubasch $\mathrm{H}$, McCormack V: Stage at breast cancer diagnosis and distance from diagnostic hospital in a periurban setting: a South African public hospital case series of over 1,000 women. Int J Cancer 2014;135:2173-2182.

25 Seedhom AE, Kamal NN: Factors affecting survival of women diagnosed with breast cancer in El-Minia Governorate, Egypt. Int J Prev Med 2011;2:131-138

26 Stapleton JM, Mullan PB, Dey S, Hablas A, Gaafar R, Seifeldin IA, Banerjee M, Soliman AS: Patient-mediated factors predicting early- and late-stage presentation of breast cancer in Egypt. Psychooncology 2011; 20:532-537.

27 Zeeneldin AA, Ramadan M, Gaber AA, Taha FM: Clinico-pathological features of breast carcinoma in elderly Egyptian patients: a comparison with the nonelderly using population-based data. J Egypt Natl Canc Inst 2013;25:5-11.

28 Ibrahim NA, Oludara MA: Socio-demographic factors and reasons associated with delay in breast cancer presentation: a study in Nigerian women. Breast 2012; 21:416-418.
29 Tesfamariam A, Gebremichael A, Mufunda J: Breast cancer clinicopathological presentation, gravity and challenges in Eritrea, East Africa: management practice in a resource-poor setting. S Afr Med J 2013;103:526528

30 Ismaili N, Elyaakoubi H, Bensouda Y, Errihani H: Demographic, clinical, pathological, molecular, treatment characteristics and outcomes of nonmetastatic inflammatory breast cancer in Morocco: 2007 and 2008. Exp Hematol Oncol 2014;3:1.

31 Kemfang Ngowa JD, Yomi J, Kasia JM, Mawamba Y, Ekortarh AC, Vlastos G: Breast cancer profile in a group of patients followed up at the radiation therapy unit of the Yaounde General Hospital, Cameroon. Obstet Gynecol Int 2011;2011:1-5.

32 Nguefack CT, Biwole ME, Massom A, Kamgaing JT, Njamen TN, Ekane GH, Obinchemti TE, Priso EB: Epidemiology and surgical management of breast cancer in gynecological department of Douala General Hospital. Pan Afr Med J 2012;13:35.

33 Mody GN, Nduaguba A, Ntirenganya F, Riviello R: Characteristics and presentation of patients with breast cancer in Rwanda. Am J Surg 2013;205:409-413.

34 Ogundiran TO, Ayandipo OO, Ademola AF, Adebamowo CA: Mastectomy for management of breast cancer in Ibadan, Nigeria. BMC Surg 2013;13:59.

35 Salem AA, Salem MA, Abbass H: Breast cancer: surgery at the South Egypt Cancer Institute. Cancers (Basel) 2010;2:1771-1778

36 Zubizarreta EH, Fidarova E, Healy B, Rosenblatt E: Need for radiotherapy in low and middle income countries - the silent crisis continues. Clin Oncol (R Coll Radiol) 2015;27:107-114.

37 Arowolo OA, Njiaju UO, Ogundiran TO, Abidoye O, Lawal OO, Obajimi M, Adetiloye AV, Im HK, Akinkuolie AA, Oluwasola A, Adelusola K, Kayode AA, Agbakwuru AE, Oduntan H, Babalola CP, Fleming G, Olopade OC, Falusi AG, Durosinmi MA, Olopade OI: Neo-adjuvant capecitabine chemotherapy in women with newly diagnosed locally advanced breast cancer in a resource-poor setting (Nigeria): efficacy and safety in a phase II feasibility study. Breast J 2013;19:470-477.

38 Kohail H, Shehata S, Mansour O, Gouda Y, Gaafar R, Hamid TA, El Nowieam S, Al Khodary A, El Zawahry H, Wareth AA, Halim IA, Taleb FA, Hamada E, Barsoum M, Abdullah M, Meshref M: A phase 2 study of the combination of gemcitabine and cisplatin in patients with locally advanced or metastatic breast cancer previously treated with anthracyclines with/without taxanes. Hematol Oncol Stem Cell Ther 2012;5:42-48.
39 Kader Y, El-Nahas T, Sakr A: Adjuvant chemotherapy for luminal A breast cancer: a prospective study comparing two popular chemotherapy regimens. Onco Targets Ther 2013;9:1073-1077.

40 Ginsberg GM, Lauer JA, Zelle S, Baeten S, Baltussen R: Cost effectiveness of strategies to combat breast, cervi$\mathrm{cal}$, and colorectal cancer in sub-Saharan Africa and Southeast Asia: mathematical modelling study. BMJ 2012;344:e614.

41 Zelle SG, Nyarko KM, Bosu WK, Aikins M, Niëns LM, Lauer JA, Sepulveda CR, Hontelez JA, Baltussen R: Costs, effects and cost-effectiveness of breast cancer control in Ghana. Trop Med Int Health 2012;17:10311043

42 Harford JB: Breast-cancer early detection in low-income and middle-income countries: Do what you can versus one size fits all. Lancet Oncol 2011;12:306-312.

43 Dye TD, Bogale S, Hobden C, Tilahun Y, Deressa T, Reeler A: Experience of initial symptoms of breast cancer and triggers for action in Ethiopia. Int J Breast Cancer 2012;2012:1-5.

44 Dye TD, Bogale S, Hobden C, Tilahun Y, Hechter V, Deressa T, Bizé M, Reeler A: Complex care systems in developing countries. Cancer 2010;116:577-585.

45 Obrist M, Osei-Bonsu E, Awuah B, Watanabe-Galloway S, Merajver SD, Schmid K, Soliman AS: Factors related to incomplete treatment of breast cancer in Kumasi, Ghana. Breast 2014;23:821-828.

46 Scherber S, Soliman AS, Awuah B, Osei-Bonsu E, Adjei E, Abantanga F, Merajver SD: Characterizing breast cancer treatment pathways in Kumasi, Ghana from onset of symptoms to final outcome: outlook towards cancer control. Breast Dis 2014;34:139-149.

47 Ntirenganya F, Petroze RT, Kamara TB, Groen RS, Kushner AL, Kyamanywa P, Calland JF, Kingham TP: Prevalence of breast masses and barriers to care: results from a population-based survey in Rwanda and Sierra Leone. J Surg Oncol 2014;110:903-906.

48 Niens LM, Nyarko KM, Zelle SG, Jehu Appiah C, Rutten FF: Equity in Ghanaian breast cancer treatmen outcomes - a modeling study in Komfo Anokye Teaching Hospital. Breast J 2014;20:100-102.

49 Ngoma T, Mandeli J, Holland JF: Downstaging cancer in rural Africa. Int J Cancer 2015;136:2875-2879.

50 Anderson BO: Breast cancer in sub-Saharan Africa: Where can we go from here? J Surg Oncol 2014;110: 901-902.

51 National Comprehensive Cancer Network: NCCN Framework for Resource Stratification of NCCN Guidelines: NCCN Framework ${ }^{\mathrm{TM}}$. www.nccn.org/ framework/ [last accessed December 5, 2015]. 